\title{
Proportion of upper extremity musculoskeletal disorders attributable to personal and occupational factors: results from the French Pays de la Loire study
}

Aboubakari Nambiema ${ }^{1 *}$, Sandrine Bertrais ${ }^{1}$, Julie Bodin ${ }^{1}$, Natacha Fouquet ${ }^{2}$, Agnès Aublet-Cuvelier ${ }^{3}$, Bradley Evanoff ${ }^{4}$, Alexis Descatha ${ }^{1,5}$ and Yves Roquelaure ${ }^{1}$

\begin{abstract}
Background: Upper extremity musculoskeletal disorders (UEMSD) are one of the most common and costly occupational health problems. We aimed to assess the population-attributable fraction (PAF) of personal and occupational risk factors associated with incident UEMSD in a working population.

Methods: From 2002 to 2005, a random sample of 3710 workers from the Pays de la Loire region in France, aged 20-59 were included by occupational physicians (OPs). Between 2007 and 2010, 1611 workers were re-examined by their OPs. Subjects free from UEMSD at baseline were included in this study (1275 workers, mean age: 38.2 years). Cox regression models with equal follow-up time and robust variance estimates were used to estimate ageadjusted and multivariable-adjusted relative risks (RRs) and their 95\% confidence intervals (Cls). Based on multivariable models, PAF associated with each factor included in the models was estimated.

Results: During the follow-up period, $143(11 \%)$ cases of UEMSD were diagnosed. PAFs for factors associated with the incident UEMSD risk were 30\% (7 to 51) for high physical exertion (RPE Borg scale $\geq 12$ ), $12 \%$ ( -0.2 to 24 ) for low social support, $7 \%$ ( -3 to 17 ) for working with arms above shoulder level ( $\geq 2 \mathrm{~h} /$ day), 20\% (12 to 28 ) for age group $\geq 45,13 \%$ (3 to 22) for the age group $35-44$, and $12 \%$ (0.3 to 24) for female gender.

Conclusions: Our study suggests that an important fraction of UEMSD can be attributed to occupational exposures after the contributions of personal and other work-related factors are considered. In terms of public health, our findings are in agreement with the ergonomic literature postulating that a high proportion of UEMSD are preventable through modifying workplace risk factors. Such information is useful to help public health practitioners and policy makers implement programs of prevention of UEMSD in the working population.
\end{abstract}

Keywords: Risk factors, Population attributable fraction, Upper extremity musculoskeletal disorders

\footnotetext{
* Correspondence: aboubakari.nambiema@univ-angers.fr

'Univ Angers, CHU Angers, Univ Rennes, Inserm, EHESP, Irset (Institut de

recherche en santé, environnement et travail) - UMR_S 1085, F-49000 Angers,

France

Full list of author information is available at the end of the article
}

\section{$\triangle B M C$}

(c) The Author(s). 2020 Open Access This article is licensed under a Creative Commons Attribution 4.0 International License, which permits use, sharing, adaptation, distribution and reproduction in any medium or format, as long as you give appropriate credit to the original author(s) and the source, provide a link to the Creative Commons licence, and indicate if changes were made. The images or other third party material in this article are included in the article's Creative Commons licence, unless indicated otherwise in a credit line to the material. If material is not included in the article's Creative Commons licence and your intended use is not permitted by statutory regulation or exceeds the permitted use, you will need to obtain permission directly from the copyright holder. To view a copy of this licence, visit http://creativecommons.org/licenses/by/4.0/. The Creative Commons Public Domain Dedication waiver (http://creativecommons.org/publicdomain/zero/1.0/) applies to the data made available in this article, unless otherwise stated in a credit line to the data. 


\section{Background}

Work-related Upper Extremity Musculoskeletal Disorders (UEMSD), which include peripheral nerve entrapments and tendon disorders, as well as nonspecific musculoskeletal regional pain disorders, are the main source of morbidity and work disability in the working populations of industrialized and developing countries [1-3]. UEMSD are a major cause of occupational disease leading to considerable human and socio-professional cost in terms of pain and discomfort in work and daily life, sometimes irreversible functional sequelae, reduced ability for work, and the risk of work disability [3-5].

The World Health Organization (WHO) defined work-related diseases as multifactorial diseases in which the work environment and the performance of work contribute significantly to the causation of the disease [6]. There is a broad consensus on the multifactorial nature of UEMSD, where both nonoccupational factors and occupational factors interact in etiology and prognosis [7-18]. Most personal susceptibility attributes (e.g. age) cannot be modified by prevention interventions or medical interventions, in contrast to potentially modifiable systemic conditions (e.g., obesity) [19, 20]. Exposure to work-related biomechanical factors (e.g., repetitive movements, forceful manual exertion) and psychosocial factors (e.g., psychological job demand, social support) could be modified by workplace-based interventions [20-23].

Identifying the modifiable risk factors for UEMSD in the workplace with the highest impact can help public health practitioners and policy makers to better target interventions at the working population level [24]. In this context, the effect of a particular risk factor depends not only on the strength of the association between the risk factor and the disease, but also on the prevalence of the risk factor. Nevertheless, when associations between a disease and a risk factor are assessed using classical statistical measures (relative risk or odds ratio), the population effect of some factors associated with high values of these estimates may be overestimated if few people are actually exposed to these factors $[25,26]$. Confounding issues should also be considered in the assessment of a risk factor effect due to the multifactorial origin of disease.

The population attributable fraction (PAF) [27] is now a commonly used measure of the population-level contribution of a risk factor on a disease. This approach has the advantage of simultaneously considering the prevalence of the exposure to risk factors within the population and their associations with the disease. Moreover, the PAF can be computed using a multivariable approach to quantify the relative impact of one or more work-related exposures, or even co-exposure, on the occurrence of UEMSD [28-33]. Assuming that other risk factors remain unchanged and that there is a causal relationship between the risk factors and UEMSD, the partial PAF [34] describes the proportion of UEMSD that could be prevented if exposure to modifiable risk factor(s) is reduced from the target working population [26]. Such information may provide an estimation of the theoretical maximum potential impact of prevention programs in the workplace [35]. The partial PAF is appropriate when the disease of interest is multifactorial, and other risk factors are not expected to change as a result of the hypothetical intervention [36]. This contribution assessment method of some risk factors to the disease burden at the population level is widely used in studies of cancer [37-44], diabetes [25], cardiovascular disease [45, 46] and hypertension [47] studies.

To date, to the best of our knowledge, no prospective study has estimated the partial PAF of work-related exposures for UEMSD in a working population. Such information may be useful to estimate the proportion of theoretically preventable UEMSD and improve prevention of UEMSD in the working population. Therefore, the aim of this study was to determine the partial PAF related to personal and occupational factors for UEMSD using the French Cosali cohort.

\section{Methods \\ Study population}

The current study used data from the Cosali cohort, which focused on musculoskeletal disorders (MSD) and working conditions among workers in the Pays de la Loire region. Between 2002 and 2005, 3710 subjects (2161 men, 1549 women) with a mean age of 38.7 (standard deviation $[\mathrm{SD}]=10.3$ ) were included. Data on personal characteristics and working conditions were collected by a self-administered questionnaire. Participants underwent a clinical examination performed by occupational physicians (OPs) in charge of the medical surveillance of salaried workers. The OPs were trained to perform the standardized clinical examination according to the European consensus criteria for evaluating the work-relatedness of UEMSD [48]. Medical conditions, such as rheumatoid arthritis and diabetes mellitus, were collected during this clinical examination. During the follow-up period between 2007 and 2010, 1611 workers were re-examined by their OP using the same procedure as for inclusion. See [49] for more details.

Each worker provided informed written consent to participate in this study and the study received approval from France's Advisory Committee on the Processing of Information in Health Research ("CCTIRS") and the National Committee for Data Protection ("CNIL"), first in 2001 and again in 2006. 


\section{Outcome definition}

Using the European consensus criteria for evaluating the work-relatedness of UEMSD [48], incident cases of UEMSD were defined as workers free of the six following clinically diagnosed UEMSD at baseline, and having at least one of them diagnosed at the follow-up: 1Rotator cuff syndrome (RCS), 2-Lateral epicondylar tendinopathy (LET), 3-Carpal tunnel syndrome (CTS), 4Ulnar tunnel syndrome, 5-Flexor-extensor peritendinitis or tenosynovitis of the forearm-wrist region, and 6-De Quervain's tenosynovitis. Details about these disorders have been previously described [50].

\section{Assessment of potential risk factors}

Three groups of potential risk factors were assessed at baseline: personal, biomechanical and psychosocial factors.

1. Personal factors included gender, age divided into three categories $(<35,35-44$ and $\geq 45$ years), overweight/obesity (body mass index (BMI) $\geq 25.0$ $\mathrm{kg} / \mathrm{m}^{2}$ ), using the World Health Organization criteria [51]), rheumatoid arthritis (yes/no) and diabetes mellitus status (yes/no).

2. Biomechanical factors (using the European consensus criteria [48]): high repetitiveness of tasks ( $\geq 4 \mathrm{~h}$ /day), use of vibrating hand tools ( $\geq 2$ $\mathrm{h} /$ day), repeated/sustained elbow movements (flexion/extension) ( $\geq 2 \mathrm{~h} /$ day), repeated/sustained posture with arms above shoulder level ( $\geq 2 \mathrm{~h} /$ day), pronation and supination movements $(\geq 2 \mathrm{~h} /$ day), wrist twisting movements ( $\geq 2 \mathrm{~h} /$ day), and use of the pinch grip ( $\geq 4 \mathrm{~h} /$ day). The definition of exposure to repeated/sustained posture with shoulder abduction included, as previously defined [49], workers who reported being exposed "rarely ( $<2$ hours/day)", "often ( $2-4$ hours/day)" or "always ( $\geq 4$ hours/day)". Using the Rating Perceived Exertion Borg scale (RPE Borg Scale) [52] ranging from 6 (no exertion at all) to 20 (maximal exertion), high perceived physical exertion was defined based on the threshold (RPE $\geq 12$ ) proposed by the French National Research and Safety Institute for the Prevention of Occupational Accidents and Diseases [53].

3. Psychosocial factors were assessed using the 26 items of the French version of the Karasek Job Content Questionnaire (JCQ) [54]. High psychological demand, low decision latitude and low social support were defined based on the median values of the national French SUMER study to classify exposed and unexposed workers [55].

\section{Statistical analysis}

Cox regression models with equal follow-up time and robust variance estimates were used to estimate ageadjusted and multivariable-adjusted relative risks (RRs) and their 95\% confidence intervals (CIs) [56] in the overall cohort. In addition, we conducted a sensitivity analysis separately for men and women to account possible differences in exposure to work constraints between genders [57]. Multivariable models included only factors significant with a Wald test $p$-value of less than 0.20 in age-adjusted models [58]. Age being recognized as a major risk factor for UEMSD in the literature [33, 59, 60], we decided to force it into multivariable models even if it was not statistically significant in age-adjusted models. Diabetes mellitus and rheumatoid arthritis were excluded from analyses due to a low number of UEMSD cases exposed (less than five UEMSD cases for each gender). Interactions between all occupational exposures have been explored to verify that these risk factors are independent factors in relation to the risk of UEMSD.

\section{Estimation of the partial population-attributable fractions (PAFs)}

Based on the multivariable models, PAFs were estimated separately for each factor included in the multivariable models. The calculation of partial PAF is recommended for multifactorial diseases when some risk factors are unmodifiable or not expected to change after intervention [36]; the calculated PAFs were considered as partial because the set of the risk factors taken into account includes unmodifiable risk factors (in theory) (e.g. age). PAFs express the percentage of UEMSD cases that could have been avoided for each risk factor separately, with the assumption of a causal relationship from the risk factors and if all other risk factors did not change.

For the estimation of PAFs and their CIs, we used the method described by Spiegelman and colleagues [61] with the SAS macro, which is fully-documented and publicly available (https://www.hsph.harvard.edu/donnaspiegelman/software/par/). The CIs were estimated using the multivariable delta method $[61,62]$ as carried out by Rajaobelina and colleagues [25]. The prevalence of the exposure and adjusted RRs were considered in PAF estimates. The PAF indicated the percentage of UEMSD cases theoretically preventable if all workers were exposed in the lowest risk group. Only PAFs for factors associated with the risk of UEMSD in multivariable models with a $p$-value of $\leq 10 \%$ have been reported in the text.

All statistical analyses were performed using the SAS software, version 9.4 (SAS Institute Inc., Cary, NC, USA). 


\section{Results}

\section{Baseline characteristics}

Of the 3170 workers included at baseline, 1228 were excluded from follow-up due to the death, retirement, parental leave, long-term sick leave, unemployment, etc. Among the remainder, 23 refused to participate in the follow-up. In addition, 848 workers did not undergo the second clinical examination because they did not have a mandatory examination scheduled between the time the OP was notified that he/she was in charge for a worker and the end of the follow-up period. A comparison of baseline characteristics of workers with follow-up and workers without follow-up (see Additional file 1, Appendix A) showed a significant difference in age between the workers who were followed up and those lost to follow-up. Workers aged $<35$ years and $\geq 45$ years were more frequent in those lost to follow-up. Moreover, workers with length of service of $<2$ years and temporary workers were more frequent among the workers lost to follow-up.

Of the 1611 workers re-examined during follow-up, 226 were with UEMSD at baseline (prevalent cases). Out of 1385 eligible participants i.e. free of UEMSD at baseline, 95 workers with missing covariates data and 15 workers with an unknown UEMSD diagnosis at followup were excluded.

A total of 1275 participants (mean age: 38.2 years, $\mathrm{SD}=8.7)$, $754(59.1 \%)$ men and 521 (40.9\%) women, were included in current analyses (Fig. 1). Participants with missing data did not differ with regards to BMI, diabetes, arthritis and seniority in current job, exposures and outcome compared to those with complete data. Participants with missing data were significantly older than those with complete data $(p=0.001)$, were more likely to be low-grade white-collar workers $(p=0.008)$ and were more likely to work in the trade and services sectors $(p=0.013)$ (see Additional file 1, Appendix B).

A description of characteristics and working conditions at baseline according to gender is provided in an additional file (see Additional file 1, Appendix C). The prevalence of being overweight/obese was higher in men than in women $(p<0.001)$. Most men worked as blue-collar workers in the industry sector, while most women were low-grade white-collar workers and worked in the trade and services sectors $(\mathrm{p}<0.001)$. No difference was observed considering the history of diabetes mellitus, rheumatoid arthritis and the seniority in the current job.

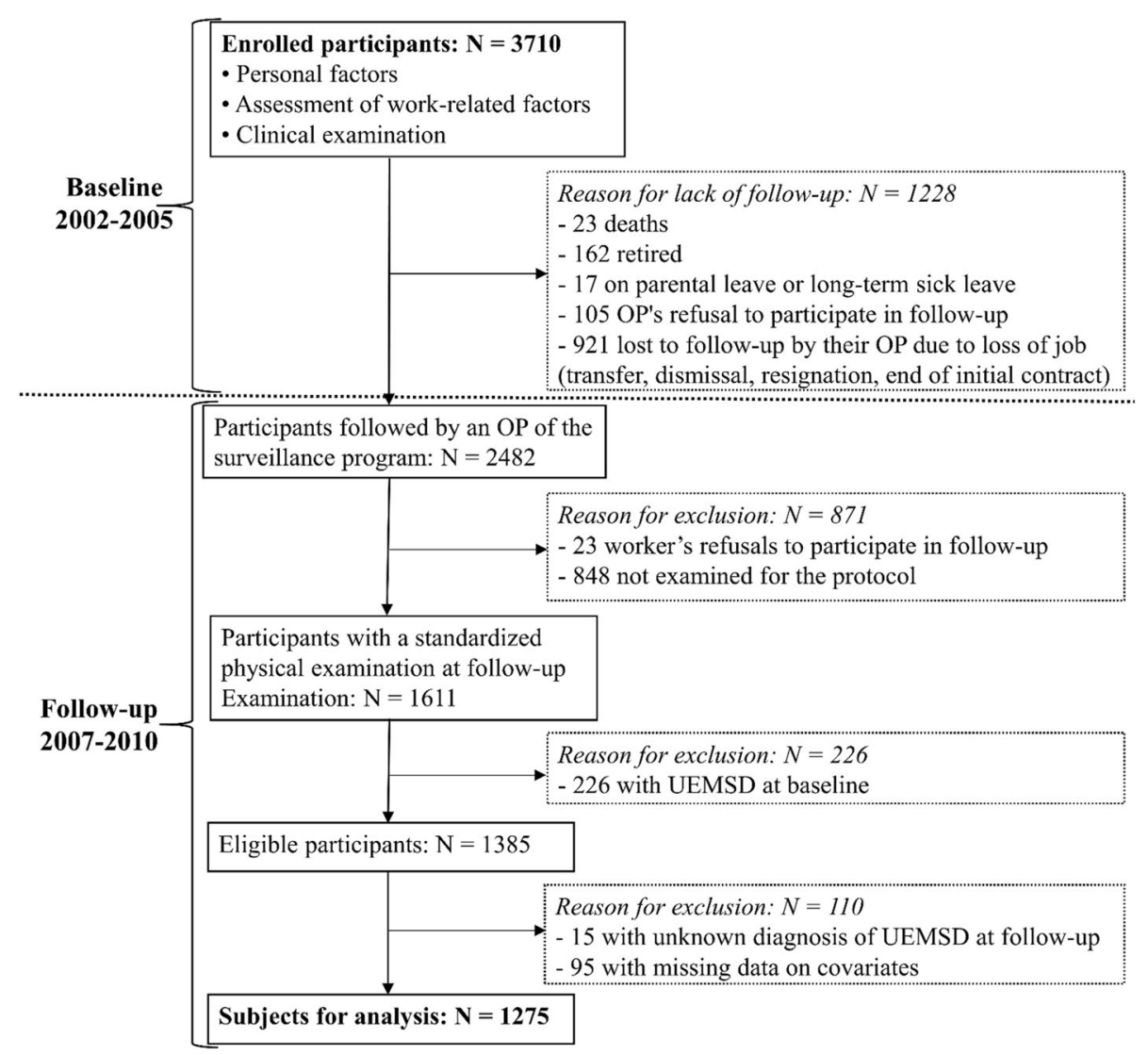

Fig. 1 Participants flow diagram 
Table 1 Distribution of the six Upper Extremity Musculoskeletal Disorders (UEMSD) among the study population

\begin{tabular}{|c|c|c|c|c|c|c|c|}
\hline & \multicolumn{2}{|c|}{ Overall population $(\boldsymbol{N}=1275)$} & \multicolumn{2}{|c|}{ Men $(\boldsymbol{N}=754)$} & \multicolumn{2}{|c|}{ Women $(\boldsymbol{N}=521)$} & \multirow[t]{2}{*}{$P$} \\
\hline & UEMSD & $\%$ & UEMSD & $\%$ & UEMSD & $\%$ & \\
\hline Rotator cuff syndrome (RCS) & 81 & 6.4 & 43 & 5.7 & 38 & 7.3 & 0.255 \\
\hline Lateral epicondylar tendinopathy (LET) & 28 & 2.2 & 22 & 2.9 & 6 & 1.2 & 0.034 \\
\hline Carpal tunnel syndrome (CTS) & 25 & 2.0 & 7 & 0.9 & 18 & 3.5 & 0.001 \\
\hline Ulnar tunnel syndrome & 12 & 0.9 & 7 & 0.9 & 5 & 1.0 & 0.956 \\
\hline De Quervain tenosynovitis & 10 & 0.8 & 4 & 0.5 & 6 & 1.2 & $0.333^{*}$ \\
\hline Flexor-extensor peritendinitis or tenosynovitis of the forearm-wrist region & 9 & 0.7 & 5 & 0.7 & 4 & 0.8 & $1.000^{*}$ \\
\hline At least one of the six UEMSD & 143 & 11.2 & 76 & 10.1 & 67 & 12.9 & 0.122 \\
\hline At least two of the six UEMSD & 20 & 1.6 & 11 & 1.5 & 9 & 1.7 & 0.704 \\
\hline
\end{tabular}

$P$ : Chi-square test for difference between genders; ${ }^{*}$ Fisher's exact test for difference between genders; $P<0.05$ are in bold

\section{UEMSD at follow up}

At least one of the six UEMSD was diagnosed at follow up in 143 workers (76 men and 67 women) out of the 1275 followed (Table 1). The incidence rate of UEMSD observed did not significantly differ between genders $(10.1 \%$ for men and $12.9 \%$ for women; $p=$ 0.122). The most common diagnoses at follow-up was RCS (incidence rate $6.4 \%$ for the overall population, $5.7 \%$ for men and $7.3 \%$ for women). LET was more common in men than in women $(2.9 \%$ vs $1.2 \%$ cases, $p=0.034$ ) while CTS was more common in women $(3.5 \%$ vs $0.9 \%$ cases; $p=0.001)$. More than one UEMSD was diagnosed at follow-up in 20 workers (incidence rate $1.6 \%$ ).

\section{Risk factors and UEMSD}

Age-adjusted models have shown that personal, biomechanical and, psychosocial risk factors were positively associated with the incident of UEMSD (with a $p$-value less than 20\%) (Table 2).

In the multivariable models (Table 3 ), the personal risk factors associated with increased risks of incident UEMSD were female gender $(\mathrm{RR}=1.36 ; \quad(95 \% \mathrm{CI}$ $1.00-1.85))$ and age $(R R=1.55(1.04-2.29)$ for the age group 35-44 and, $R R=2.17(1.47-3.19)$ for the age group 245 ). The occupational factors positively associated with an increased risk of UEMSD were high perceived physical exertion $(\mathrm{RR}=1.80 \quad(1.24-2.62)$, repeated/sustained posture with arms above shoulder level $(R R=1.59(1.06-2.37))$ and low social support $(\mathrm{R} R=1.37(1.01-1.87))$. No interaction was found between occupational exposures.

The sensitivity analysis (Table 3) showed that, in male workers, high perceived physical exertion was associated with an increased risk of UEMSD $(R R=1.80(1.24-$ 2.62)). The risk of UEMSD associated with low social support was of the borderline of significance $(R R=1.41$ (0.93-2.15)). In female workers, being overweight or obese was associated with an increased risk of UEMSD
$(\mathrm{RR}=1.74(1.10-2.75))$. The association with arms above shoulder level $(\mathrm{RR}=1.6(0.9-2.6))$ and shoulder abduction $(R R=1.6(0.9-2.7))$ approached statistical significance but the $95 \% \mathrm{CI}$ included the value one.

\section{Partial population attributable fraction (PAF) for UEMSD risk factors}

Considering the PAF of UEMSD for occupational risk factors, a high perceived physical exertion explained 30\% (7 to 51) of cases (Fig. 2a). An estimated of 7\% (-3 to $17)$ and $12 \%$ ( -0.2 to 24$)$ of UEMSD cases were attributable to working with arms above shoulder level $(\geq 2 \mathrm{~h} /$ day) and low social support, respectively. Concerning personal risk factors PAFs were of $12 \%$ (95\% CI: 0.3 to 24) for female gender, $13 \%$ (3 to 22) for the age group $35-44$, and $20 \%$ (12 to 28 ) for the age group $\geq 45$.

Sensitivity analysis (Fig. 2b) in men showed that a high perceived physical exertion was the leading risk factor with a PAF of $43 \%$ (95\% CI: 13 to 65), followed by the age group 35-44 (PAF: 26\% (15 to 36)), the age group 35-44 (PAF: 17\% (3 to 30)) and, low social support (PAF: $14 \%$ ( -5 to 32$)$ ). In women, the PAF was of $17 \%$ ( -2 to 33) for being overweight or obese, followed by working posture with shoulder abduction (15\% (- 10 to $38)$ ) and, working posture with arms above shoulder level (7\% (-6 to 20$))$.

\section{Discussion}

For multifactorial diseases, such as UEMSD, the PAFs allows an estimation of the contribution of the workrelated and non-work-related risk factors to the burden of disease in the working population. In the multivariable models, our results showed that the main risk factors of UEMSD were, in decreasing order, high perceived physical exertion (PAF: 30\%), the age group $\geq 45$ (PAF: 20\%), age group 35-44 (PAF: 13\%), female gender (PAF: 12\%), low social support (PAF: 12\%) and, working with arms above shoulder level (PAF: 7\%). 


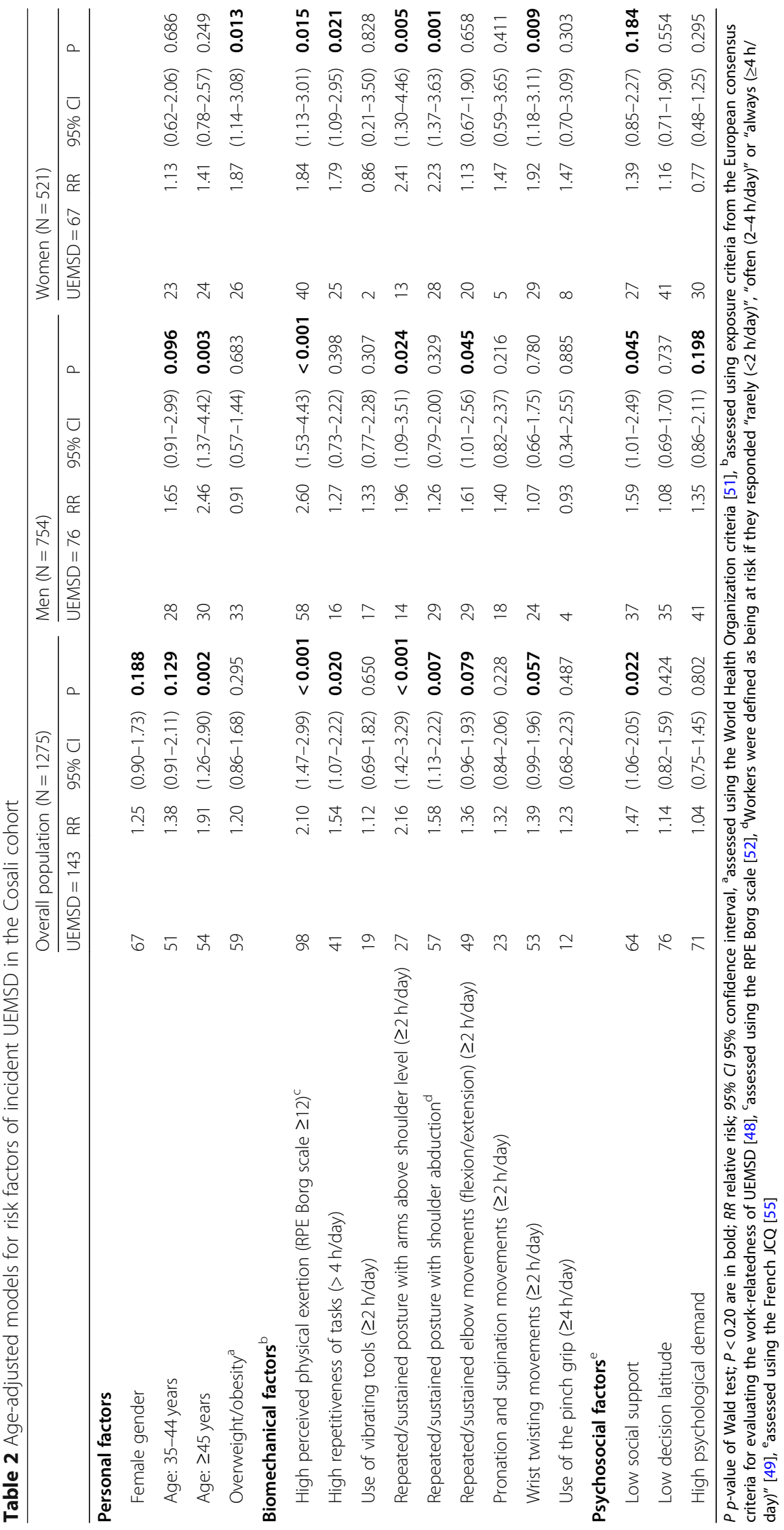




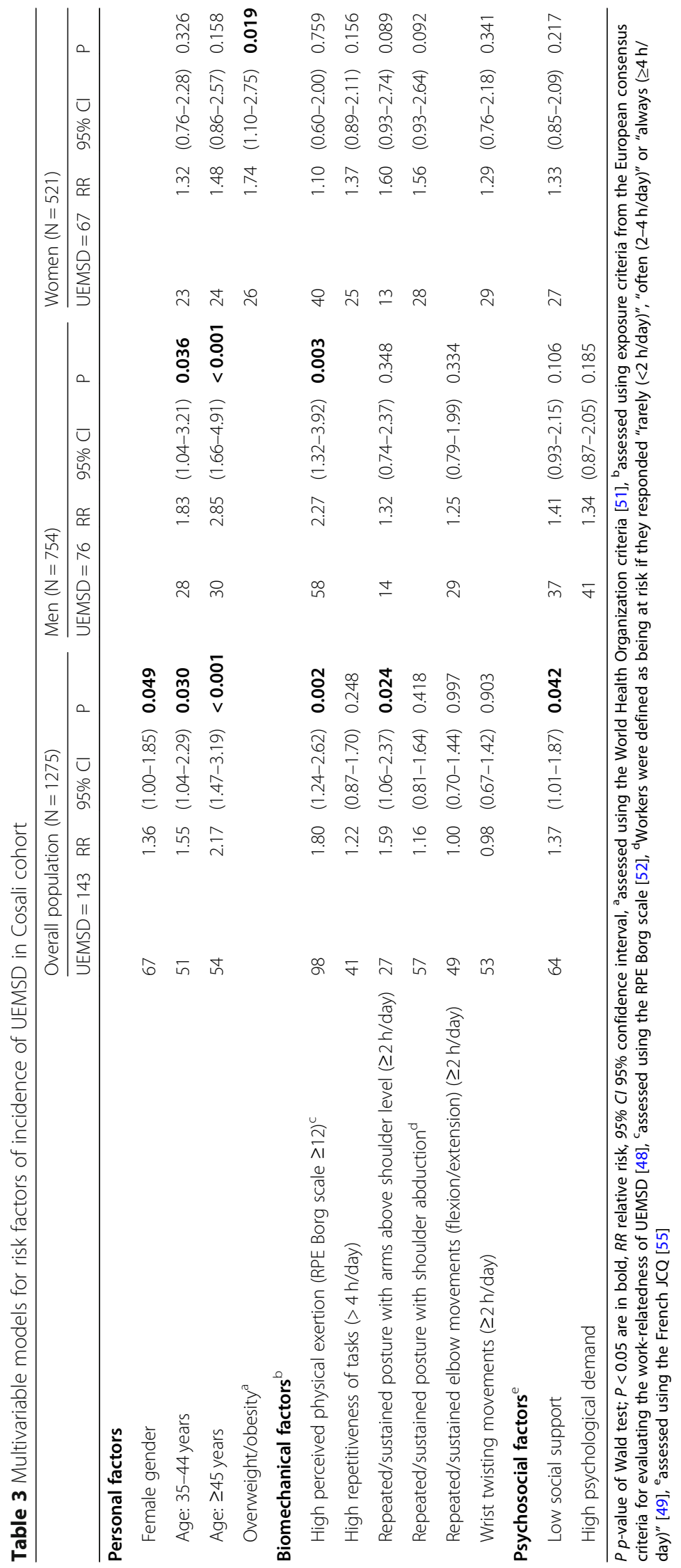




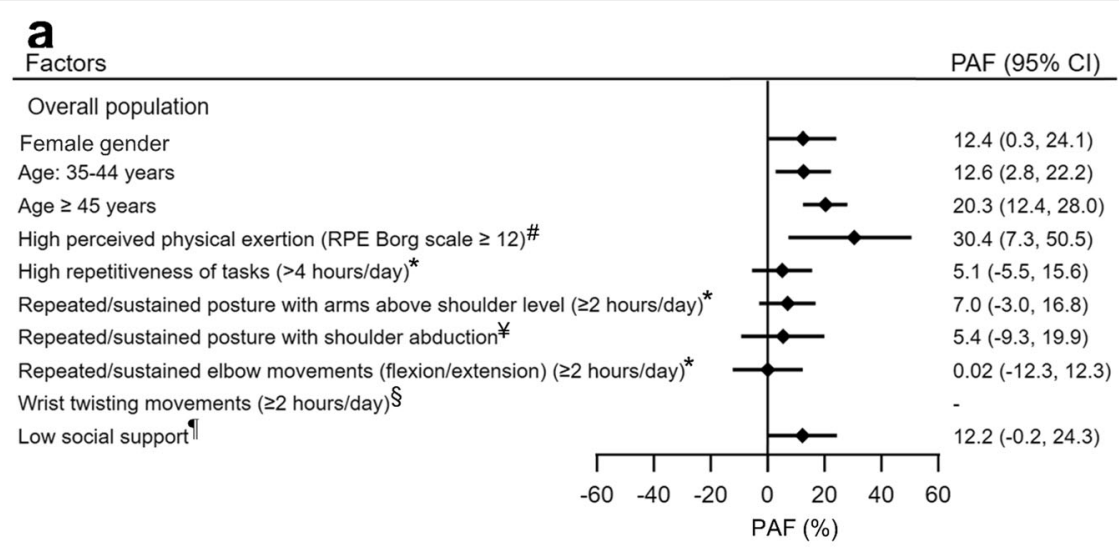

b

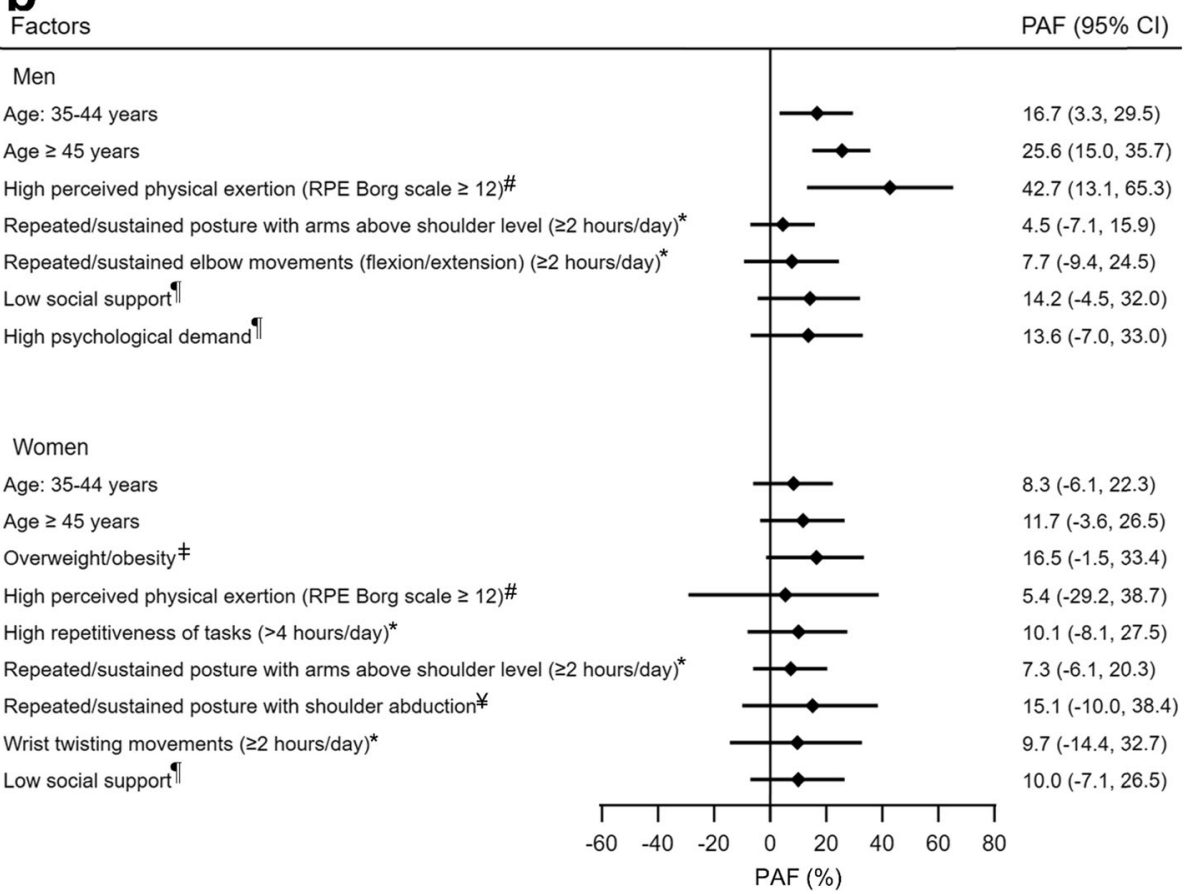

Fig. 2 Population-attributable fraction (PAF) for UEMSD risk factors, adjusting for all factors shown, in Cosali cohort. The PAF was calculated using the lowest risk group for each factor as the reference group, with all other factors remaining unchanged. a Overall population, $\mathbf{b}$ Stratify by gender, "assessed using the RPE Borg scale [52], " assessed using exposure criteria from the European consensus criteria for evaluating the workrelatedness of UEMSD [48], \$ relative risk $<1$ and the PAF was not calculated, "assessed using the French JCQ [55], " assessed using the World Health Organization criteria [51], ${ }^{\ddagger}$ Workers were defined as being at risk if they reported being exposed "rarely ( $<2$ hours/day)", "often ( $2-4$ hours/ day)" or "always ( $\geq 4$ hours/day)" [49]

\section{Literature comparison}

There are extensive literature demonstrating the links between personal factors and work-related risk factors and UEMSD [2, 7, 8, 10, 11, 14-18, 50, 63-72]. Most studies of provided RRs or odds ratios associated with these personal or work-related risk factors. Only few studies assessed the proportion of UEMSD cases attributable to these risk factors and their contribution to the burden of UEMSD in the working population $[28,30,73]$. Most of them $[2,29,30,74]$ have quantified the impact of work-related exposures on the occurrence of UEMSD only in exposed population. One study [28] estimated PAFs for CTS ranging from 19 to $50 \%$ according to occupational categories and from 5 to $17 \%$ according to industrial sectors.

In our study, age $\geq 45$ years contributed importantly to the incidence of UEMSD: $20 \%$ of cases of UEMSD that could be attributed to this age group. However, this major personal factor is unmodifiable. In this case, age can be considered as a marker of the degenerative 
process of the periarticular soft tissues, but also as a marker of the cumulative exposure of work-related risk factors [75]. Female gender was associated with $12 \%$ of UEMSD cases occurring in the working population. This PAF was lower than the one (34\%) associated with CTS in a cohort study conducted in Italy (OCTOPUS study) [33].

Considering work-related exposures, our results showed that the risk of UEMSD was associated with high physical exertion, working with arms above shoulder level and, low social support. These findings are consistent with a large body of epidemiologic studies that evaluated the relation between UEMSD and occupational exposures $[7,8,11,14,16-18,66,67,71,76,77]$.

Regarding PAFs, we found high PAFs for both biomechanical and psychosocial factors, after adjustment for personal risk factors. Concerning biomechanical factors, findings suggested that nearly $30 \%$ of UEMSD could potentially be avoided by lowering the physical exertion on the RPE Borg scale below 12 (RPE Borg scale range $=6$ to 20). The United States National Research Council and Institute of Medicine [2] report on MSD estimated an attributable fraction (AF) for work-related upper extremity disorders risk in exposed population at the workplace. AF estimates were $78 \%$ for high forces, between 28 and $52 \%$ for low social support, and between 33 and $58 \%$ for high psychological demand, based on how specifically the exposure and the outcome were defined. A Canadian study [30] estimated AF in exposed people by comparing the incidence of CTS surgery among different working groups, using non-manual workers as the reference population. Among manual workers in Montreal, $55 \%$ of surgical CTS in women and $76 \%$ in men were attributable to work. A Swedish study based on the review of epidemiologic studies [74] concluded that at least $50 \%$, and as much as $90 \%$, of all of the CTS cases in working populations exposed to physical work load factors such as repetitive and forceful gripping appeared to be attributable to physical work load. A French study [29] has shown that a proportion of CTS ranging between 36 and 93\% could be attributed to industry sectors and occupational categories. The findings of these studies support the results observed in the working population characterized by a high contribution of work-related factors, especially in male workers. The current study found a PAF of $7 \%$ that could be attributed to working with arms above shoulder level. A prospective cohort study of Harkness et al. [78] found an association between new of onset shoulder pain and working with hands above shoulder. A recent systematic review and meta-analysis [16] have revealed moderate evidence for associations between shoulder disorders and arm-hand elevation.
For psychosocial factors in this study, we demonstrated that $12 \%$ of UEMSD cases could be attributed to low social support, although the PAF did not reach the statistical level of significance. However, epidemiologic investigations have demonstrated the relationship between some types of UEMSD and work-related psychosocial factors. A systematic literature review of van Rijn et al. [17] showed that psychosocial factors including low social support at work were associated with an increased occurrence of LET. Moreover, a pooled study cohort [68] has reported that workers with high social support in the workplace had half the risk of CTS incidence compared with those with low social support.

Sensitivity analyses were stratified by gender to account possible differences in personal risk factors and exposure to occupational hazards exposure between men and women [57]. In men, factors affected the risk of UEMSD were high perceived physical exertion, low social support, and age. In women, these factors were working with shoulder abduction, working with arms above shoulder level, and overweight/obese. The OCTOPUS study found a PAF of $30 \%$ for being overweight/ obese associated with CTS risk [33]. Several patho- or biomechanical mechanisms might be involved in relationship between overweight/obesity and the risk of UEMSD in women. Obesity may increase the risk of CTS $[68,79]$, a disorder more frequent in the women in our study, due to the accumulation of fat tissue within the carpal tunnel; this has been hypothesized to increase intra-carpal tunnel pressure $[80,81]$. Secondly, obesity may increase the risk of rotator cuff tendinopathy [82, 83] and LET [84] due to failure of tendon repair in obese workers. Another explanation is that severe obesity may modify the worker's anthropometric characteristics leading to (i) increased shoulder abduction at rest and in activity and (ii) increased moment of forces applied on the shoulder joint and rotator cuff tendons due to increased weight of the upper limb [85]. Such mechanisms may be particularly important in workers who are exposed to high physically demanding jobs [86]. Our study found a noticeable PAF value (15\%) for working with shoulder abduction in women, even if this result was not statistically significant possibly due lack of statistical power (only 38 cases of RCS). This PAF estimate is consistent with recent meta-analyses showing increased risks of rotator cuff tendinopathy with shoulder abduction $[16,87]$.

\section{Strengths and limitations}

There were some potential limitations of our study that could have affected the results. Of the 3710 workers initially included, about 57\% (young workers, those in short-time working or with a short period of service) did not undergo the follow-up clinical examination. According a longitudinal study of MSD [88], differences in 
occupational conditions between participants and those lost to follow-up did not significantly influence estimates of risk ratios. Diabetes mellitus and rheumatoid arthritis which are associated with UEMSD in the literature were not studied due to a low number of UEMSD cases exposed (less than five UEMSD cases in each gender) (see Additional file 1, Appendix C).

The thresholds used to define exposure levels may influence PAF estimates [89]. However, these cut-points were chosen based on the literature and public health recommendations. A second limitation is that the assessment of exposures was based on self-reported exposure, whereas assessing UEMSD cases was based on clinical examination. The non-differential misclassification of exposures may have occurred due to workers' inability to precisely recall or describe their current work exposures. Lack of measurement precision may also have occurred when quantifying exposures due to the 1 to 4 point ordinal scale used in exposure questions, except for physical exertion which was assessed using the RPE Borg Scale [52]. To the extent that the risk of UEMSD is increased by cumulative or chronic physical exposures, our analyses may have underestimated the true contribution of work exposures to the incidence of UEMSD in our study population. This may be especially true for RCS, as studies of occupational risk factors for shoulder pain have consistently identified duration of employment as a risk factor [90]. Furthermore, it's important to note that the PAF associated with single risk factors cannot be added to obtain a combined PAF associated with a combination of risk factors and that a combined PAF cannot be subtracted from $100 \%$ to determine the "unexplained" proportion of cases [26]. Further studies on a larger sample could appropriately assess the PAF associated with co-exposures. Despite the importance of PAF estimates, which are useful to rank risk factors, we should note that public health interventions are not possible for all factors (e.g. age) and a total elimination of risk factors in the population level is practically impossible. Finally, we should note that, the estimation of PAFs was assumed to have a causal relationship between exposure and UEMSD and should therefore be interpreted with caution.

The study has also several strengths. A major strength is that the study included a representative sample of the working population at baseline. Secondly, the definition of incidence cases was based on a standardized clinical examination performed by a trained occupational physician. Due to the prospective design of the study, exposure information gathered prior to UEMSD diagnosis resulted in low risk of recall bias. Another strength is the formula used to estimate the PAF from multivariable regression models, allowing a non-biased estimation of adjusted PAF [26]. This regression-based PAF estimation method allows to control confounding and interaction, and can be used for the main epidemiologic designs [91].

\section{Conclusions}

Our study suggests that an important fraction of UEMSD can be attributed to occupational exposures such as physical exertion and low social support, after the contributions of personal and other work-related factors are considered. Potentially modifiable personal factors, such as being overweight or obesity, contribute to the population burden of UEMSD in women. Despite the lack statistical significance of the PAF associated with factors such as working with shoulder abduction in women, interventions should still consider these factors recognized in literature as being associated with UEMSD. In terms of public health, the findings of the present study are in agreement with the ergonomic literature postulating that a high proportion of UEMSD are preventable through modifying workplace risk factors [92, 93]. Interventions should still consider recognizable risk factors that have been found to be associated with UEMSD in the literature. Such information is useful to help public health practitioners and policy makers implement programs of prevention of UEMSD in the working population.

\section{Supplementary information}

Supplementary information accompanies this paper at https://doi.org/10. 1186/s12889-020-08548-1.

Additional file $\mathbf{1}$ : Appendix A. Comparison of baseline characteristics of workers with follow-up and workers without follow-up. Appendix B. Comparison of baseline characteristics, outcome and working conditions between respondents with complete and missing data. Appendix C.

Characteristics and working conditions of the study population at baseline according to gender.

\section{Abbreviations}

UEMSD: Upper extremity musculoskeletal disorders; RCS: Rotator cuff syndrome; CTS: Carpal tunnel syndrome; LET: Lateral epicondylar tendinopathy; OP: Occupational physician; BMI: Body mass index; RPE: Rating perceived exertion; RR: Relative risk; $95 \% \mathrm{Cl}$ : 95\% confidence interval; PAF: Population-attributable fraction; WHO: World Health Organization

\section{Acknowledgments}

We acknowledge the following occupational physicians involved in the sentinel network: Doctors Abonnat, Banon, Bardet, Benetti, Becquemie, Bertin, Bertrand, Bidron, Biton, Bizouarne, Boisse, Bonamy, Bonneau, Bouguer, Bouguer-Diquelou, Bourut-Lacouture, Breton, Caillon, Cesbron, Chisacoff, Chotard, Compain, Coquin-Geogeac, Cordes, Couet, Coutand, Daniellou, Darcy, Davenas, De Lescure, Delansalut, Dupas, Evano, Fache, Fontaine, Frampas-Chotard, Guiller, Guillimin, Harinte, Harrigan, Hervio, Hirigoyen, Jahan, Joliveau, Jube, Kalfon, Laine-Colin, Laventure, Le Dizet, Lechevalier, Leclerc, Ledenvic, Leroux, Leroy-Maguer, Levrard, Levy, Logeay, Lucas, Mallet, Martin, Mazoyer, Meritet, Michel, Migne-Cousseau, Moisan, Page, Patillot, Pinaud, Pineau, Pizzala, Plessis, Plouhinec, Raffray, Roussel, Russu, Saboureault, Schlindwein, Soulard, Thomson, Treillard, Tripodi. We would like to express our sincere gratitude to Dr. Susan Stock for her advice and constructive suggestions in the selection of some analytical variables. We also thank Mr. Jean 
François Chastang who provided us with valuable assistance and advice on the use of different statistical methods.

\section{Conflict of interest}

The authors have none to declare.

\section{Authors' contributions}

YR and NF participated to the design of the study. AN analyzed the data, performed the statistical analysis and wrote the manuscript. YR had full access to all of the data in the study and takes responsibility for the integrity of the data. SB, JB, NF, AAC, AD, BE and YR reviewed and commented on the final manuscript. All authors read and approved the final manuscript to be published.

\section{Funding}

This project was supported by Santé publique France, the French national public health agency, Saint-Maurice, France (Grant 9/25/2002-5 "réseau expérimental de surveillance des troubles musculo-squelettiques") and the French National Research Program for Environmental and Occupational Health of Anses (Grant EST-2016/1/42).

None of the mentioned sources of funding had any role in the design, analysis or writing of this article.

\section{Availability of data and materials}

The datasets used and/or analyzed during the current study are available from the corresponding author on reasonable request.

\section{Ethics approval and consent to participate}

Each worker provided informed written consent to participate in this study, and the study received the approval of the French Advisory Committee on the Processing of Information in Health Research ("CCTIRS") and the National Committee for Data Protection ("CNIL").

\section{Consent for publication}

Not applicable.

\section{Competing interests}

The authors declare that they have no competing interests associated with this manuscript.

\section{Author details}

${ }^{1}$ Univ Angers, CHU Angers, Univ Rennes, Inserm, EHESP, Irset (Institut de recherche en santé, environnement et travail) - UMR_S 1085, F-49000 Angers, France. ${ }^{2}$ Santé publique France, the French national public health agency, Direction of Occupational Health, EpiprevTMS team associated to the University of Angers, F-49000 Angers, France. ${ }^{3}$ INRS, Département Homme au travail, 1 rue du Morvan CS60027, 54519 Vandoeuvre, France. ${ }^{4}$ Division of General Medical Sciences, Washington University School of Medicine, St. Louis, St. Louis, MO 13 63310, USA. Inserm, UMS 011, unité cohortes épidémiologiques en population, Villejuif, France.

\section{Received: 29 April 2019 Accepted: 18 March 2020}

Published online: 06 April 2020

\section{References}

1. Ha C, Roquelaure Y, Leclerc A, Touranchet A, Goldberg M, Imbernon E. The French Musculoskeletal Disorders Surveillance Program: Pays de la Loire network. Occup Environ Med. 2009;66:471-9.

2. National Research Council (U.S.), Institute of Medicine (U.S.). Musculoskeletal disorders and the workplace: low back and upper extremities. Washington, D.C: National Academy Press; 2001.

3. Summers K, Jinnett K, Bevan S. Musculoskeletal disorders, workforce health and productivity in the United States. Musculoskelet Disord. 2015. https:// pdfs.semanticscholar.org/99e7/db4d88d398a612aa4d16fb0fd16425a86560. pdf?_ga=2.50245743.895633849.1584971278-1374044221.1584971278.

4. Bevan S. Economic impact of musculoskeletal disorders (MSDs) on work in Europe. Best Pract Res Clin Rheumatol. 2015;29:356-73.

5. Roquelaure Y. Musculoskeletal disorders: a major challenge for occupational risk prevention in Europe. Brussels: ETUl; 2015. https://www.etui.org/ Publications2/Policy-Briefs/European-Economic-Employment-and-Social-
Policy/Musculoskeletal-disorders-a-major-challenge-for-occupational-riskprevention-in-Europe.

6. WHO Expert Committee on Identification and Control of Work-Related Diseases \& World Health Organization. Identification and control of workrelated diseases : report of a WHO expert committee. Geneva: World Health Organization; 1985. [meeting held in Geneva from 28 November to 2 December 1983. http://www.who.int/iris/handle/10665/40176. Accessed 26 Feb 2019.

7. da Costa BR, Vieira ER. Risk factors for work-related musculoskeletal disorders: a systematic review of recent longitudinal studies. Am J Ind Med. 2010;53:285-323.

8. Descatha A, Albo F, Leclerc A, Carton M, Godeau D, Roquelaure Y, et al. Lateral Epicondylitis and physical exposure at work? A review of prospective studies and meta-analysis. Arthritis Care Res. 2016;68:1681-7.

9. Hauke A, Flintrop J, Brun E, Rugulies R. The impact of work-related psychosocial stressors on the onset of musculoskeletal disorders in specific body regions: a review and meta-analysis of 54 longitudinal studies. Work Stress. 2011;25:243-56.

10. Jackson JA, Olsson D, Burdorf A, Punnett L, Järvholm B, Wahlström J. Occupational biomechanical risk factors for radial nerve entrapment in a 13year prospective study among male construction workers. Occup Environ Med. 2019;76:326-31.

11. Keir PJ, Farias Zuniga A, Mulla DM, Somasundram KG. Relationships and mechanisms between occupational risk factors and distal upper extremity disorders. Hum Factors. 2019. https://doi.org/10.1177/0018720819860683.

12. Kozak A, Schedlbauer G, Wirth T, Euler U, Westermann C, Nienhaus A. Association between work-related biomechanical risk factors and the occurrence of carpal tunnel syndrome: an overview of systematic reviews and a meta-analysis of current research. BMC Musculoskelet Disord. 2015;16:231.

13. Lang J, Ochsmann E, Kraus T, Lang JWB. Psychosocial work stressors as antecedents of musculoskeletal problems: a systematic review and meta-analysis of stability-adjusted longitudinal studies. Soc Sci Med 1982. 2012;75:1163-74.

14. Lund CB, Mikkelsen S, Thygesen LC, Hansson G- $\AA$, Thomsen JF. Movements of the wrist and the risk of carpal tunnel syndrome: a nationwide cohort study using objective exposure measurements. Occup Environ Med. 2019;76:519-26.

15. Roquelaure $Y$, Ha C, Rouillon C, Fouquet N, Leclerc A, Descatha A, et al. Risk factors for upper-extremity musculoskeletal disorders in the working population. Arthritis Care Res. 2009;61:1425-34.

16. van der Molen HF, Foresti C, Daams JG, Frings-Dresen MHW, Kuijer PPFM. Work-related risk factors for specific shoulder disorders: a systematic review and meta-analysis. Occup Environ Med. 2017;74:745-55.

17. van Rijn RM, Huisstede BMA, Koes BW, Burdorf A. Associations between work-related factors and specific disorders at the elbow: a systematic literature review. Rheumatology. 2009;48:528-36.

18. van Rijn RM, Huisstede BM, Koes BW, Burdorf A. Associations between workrelated factors and specific disorders of the shoulder - a systematic review of the literature. Scand J Work Environ Health. 2010;36:189-201.

19. Feltner C, Peterson K, Palmieri Weber R, Cluff L, Coker-Schwimmer E, Viswanathan $M$, et al. The effectiveness of Total worker health interventions: a systematic review for a National Institutes of Health pathways to prevention workshop. Ann Intern Med. 2016;165:262-9.

20. Van Eerd D, Munhall C, Irvin E, Rempel D, Brewer S, van der Beek AJ, et al. Effectiveness of workplace interventions in the prevention of upper extremity musculoskeletal disorders and symptoms: an update of the evidence. Occup Environ Med. 2016;73:62-70.

21. Aubé K, Duchaine CS, Dionne CE, Vézina M, Mantha-Bélisle M-M, SultanTaiieb $\mathrm{H}$, et al. Evaluation of the Quebec healthy Enterprise standard: effect on adverse physical and psychosocial work factors and work-related musculoskeletal problems. J Occup Environ Med. 2019;61:203-11.

22. Kennedy CA, Amick BC, Dennerlein JT, Brewer S, Catli S, Williams R, et al. Systematic review of the role of occupational health and safety interventions in the prevention of upper extremity musculoskeletal symptoms, signs, disorders, injuries, claims and lost time. J Occup Rehabil. 2010;20:127-62.

23. Stock SR, Nicolakakis N, Vézina N, Vézina M, Gilbert L, Turcot A, et al. Are work organization interventions effective in preventing or reducing workrelated musculoskeletal disorders? A systematic review of the literature. Scand J Work Environ Health. 2018:44:113-33.

24. Roquelaure Y, Fouquet N, Chazelle E, Descatha A, Evanoff B, Bodin J, et al. Theoretical impact of simulated workplace-based primary prevention of carpal tunnel syndrome in a French region. BMC Public Health. 2018;18:426. 
25. Rajaobelina K, Dow C, Romana Mancini F, Dartois L, Boutron-Ruault M-C, Balkau B, et al. Population attributable fractions of the main type 2 diabetes mellitus risk factors in women: findings from the French E3N cohort: population attributable fractions in T2DM. J Diabetes. 2018. https://doi.org/ 10.1111/1753-0407.12839

26. Rockhill B, Newman B, Weinberg C. Use and misuse of population attributable fractions. Am J Public Health. 1998;88:15-9.

27. Levin ML. The occurrence of lung cancer in man. Acta - Unio Int Contra Cancrum. 1953;9:531-41

28. Roquelaure $\mathrm{Y}, \mathrm{Ha}$ C, Fouquet N, Descatha A, Leclerc A, Goldberg M, et al. Attributable risk of carpal tunnel syndrome in the general population: implications for intervention programs in the workplace. Scand J Work Environ Health. 2009;35:342-8.

29. Roquelaure $Y, \mathrm{Ha}$ C, Nicolas G, Pélier-Cady M, Mariot C, Descatha A, et al. Attributable risk of carpal tunnel syndrome according to industry and occupation in a general population. Arthritis Rheum. 2008;59:1341-8.

30. Rossignol M, Stock S, Patry L, Armstrong B. Carpal tunnel syndrome: what is attributable to work? Montreal Stud Occup Environ Med. 1997;54:519-23.

31. Tanaka S, Petersen M, Cameron L. Prevalence and risk factors of tendinitis and related disorders of the distal upper extremity among U.S. workers: comparison to carpal tunnel syndrome. Am J Ind Med. 2001;39:328-35.

32. van der Molen HF, Hulshof CT, Kuijer PPF. How to improve the assessment of the impact of occupational diseases at a national level? The Netherlands as an example. Occup Environ Med. 2019;76:30-2.

33. Violante FS, Farioli A, Graziosi F, Marinelli F, Curti S, Armstrong TJ, et al. Carpal tunnel syndrome and manual work: the OCTOPUS cohort, results of a ten-year longitudinal study. Scand J Work Environ Health. 2016;42:280-90.

34. Bruzzi P, Green SB, Byar DP, Brinton LA, Schairer C. Estimating the population attributable risk for multiple risk factors using case-control data. Am J Epidemiol. 1985;122:904-14.

35. Punnett $\mathrm{L}$, Wegman $\mathrm{DH}$. Work-related musculoskeletal disorders: the epidemiologic evidence and the debate. J Electromyogr Kinesiol. 2004;14: $13-23$.

36. Wong BHW, Peskoe SB, Spiegelman D. The effect of risk factor misclassification on the partial population attributable risk. Stat Med. 2018; 37:1259-75.

37. Tuyns AJ, Péquignot G, Abbatucci JS. Oesophageal cancer and alcohol consumption; importance of type of beverage. Int J Cancer. 1979;23:443-7.

38. Parkin DM, Boyd L, Walker LC. The fraction of cancer attributable to lifestyle and environmental factors in the UK in 2010. Br J Cancer. 2011:105:S77-81.

39. Wang JB, Jiang Y, Liang H, Li P, Xiao HJ, Ji J, et al. Attributable causes of cancer in China. Ann Oncol. 2012;23:2983-9.

40. Schottenfeld D, Beebe-Dimmer JL, Buffler PA, Omenn GS. Current perspective on the global and United States Cancer burden attributable to lifestyle and environmental risk factors. Annu Rev Public Health. 2013;34:97117.

41. Dartois L, Fagherazzi G, Baglietto L, Boutron-Ruault M-C, Delaloge S, Mesrine $S$, et al. Proportion of premenopausal and postmenopausal breast cancers attributable to known risk factors: estimates from the E3N-EPIC cohort: population-attributable fraction for invasive breast cancer. Int J Cancer. 2016;138:2415-27.

42. Gassama M. Estimation du risque attribuable et de la fraction préventive dans les études de cohorte. 2016. https://tel.archives-ouvertes.fr/tel-016992 79/document. Accessed 11 Jun 2018.

43. Engmann NJ, Golmakani MK, Miglioretti DL, Sprague BL, Kerlikowske K, for the Breast Cancer Surveillance Consortium. Population-Attributable Risk Proportion of Clinical Risk Factors for Breast Cancer. JAMA Oncol. 2017;3:1228.

44. Islami F, Goding Sauer A, Miller KD, Siegel RL, Fedewa SA, Jacobs EJ, et al. Proportion and number of cancer cases and deaths attributable to potentially modifiable risk factors in the United States: potentially preventable cancers in US. CA Cancer J Clin. 2018;68:31-54

45. Azimi SS, Khalili D, Hadaegh F, Yavari P, Mehrabi Y, Azizi F. Calculating population attributable fraction for cardiovascular risk factors using different methods in a population based cohort study. J Res Health Sci. 2014;15:22-7.

46. Pirani N, Khiavi FF. Population attributable fraction for cardiovascular diseases risk factors in selected countries: a comparative study. Mater SocioMed. 2017;29:35-9.

47. Mohammadi M, Mirzaei M. Population-attributable fraction of hypertension associated with obesity, abdominal obesity, and the joint effect of both in the central provinces of Iran. J Epidemiol Glob Health. 2017;7:71-9.
48. Sluiter JK, Rest KM, Frings-Dresen MH. Criteria document for evaluating the work-relatedness of upper-extremity musculoskeletal disorders. Scand J Work Environ Health. 2001;27:1-30 \& 43-5.

49. Bodin J, Ha C, Petit Le Manac'h A, Sérazin C, Descatha A, Leclerc A, et al. Risk factors for incidence of rotator cuff syndrome in a large working population. Scand J Work Environ Health. 2012;38:436-46.

50. Roquelaure $Y$, Ha C, Leclerc A, Touranchet A, Sauteron M, Melchior M, et al. Epidemiologic surveillance of upper-extremity musculoskeletal disorders in the working population. Arthritis Care Res. 2006;55:765-78.

51. WHO. Obesity: preventing and managing the global epidemic: report of a WHO consultation. Geneva: World Health Organization; 2000.

52. Borg GAV. Psychophysical bases of perceived exertion. Med Sci Sports Exerc 1982:14:377-81.

53. INRS. Méthode d'analyse de la charge physique de travail - ED 61611 ère édition. 2014; 1ère édition (2014)-réimpression 10/2015:43.

54. Karasek RA, Brisson C, Kawakami N, Houtman I, Bongers P, Amick B. The job content questionnaire (JCQ): an instrument for internationally comparative assessments of psychosocial job characteristics. J Occup Health Psychol. 1998;3:322-55.

55. Niedhammer I, Chastang J-F, Gendrey L, David S, Degioanni S. Psychometric properties of the French version of Karasek's "job content questionnaire" and its scales measuring psychological pressures, decisional latitude and social support: the results of the SUMER. Santé Publique. 2006;18:413-27.

56. Barros AJ, Hirakata VN. Alternatives for logistic regression in cross-sectional studies: an empirical comparison of models that directly estimate the prevalence ratio. BMC Med Res Methodol. 2003;3:21.

57. Silverstein B, Fan ZJ, Smith CK, Bao S, Howard N, Spielholz P, et al. Gender adjustment or stratification in discerning upper extremity musculoskeletal disorder risk? Scand J Work Environ Health. 2009;35:113-26.

58. Bouyer J, Hémon D, Cordier S, Derriennic F, Stücker I, Stengel B, et al. Analyse multivariée - Principes généraux. In: Epidémiologie: principes et méthodes quantitatives. Lavoisier. Paris: Editions INSERM; 2009. p. 240-265.

59. Fan Z, Silverstein BA, Bao S, Bonauto DK, Howard NL, Smith CK. The association between combination of hand force and forearm posture and incidence of lateral epicondylitis in a working population. Hum Factors. 2014;56:151-65.

60. Herquelot E, Bodin J, Roquelaure $Y, H a$ C, Leclerc A, Goldberg M, et al. Work-related risk factors for lateral epicondylitis and other cause of elbow pain in the working population. Am J Ind Med. 2013;56:400-9.

61. Spiegelman D, Hertzmark E, Wand HC. Point and interval estimates of partial population attributable risks in cohort studies: examples and software. Cancer Causes Control. 2007;18:571-9.

62. Benichou J, Gail MH. Variance calculations and confidence intervals for estimates of the attributable risk based on logistic models. Biometrics. 1990;46:991.

63. Coronado RA, Seitz AL, Pelote E, Archer KR, Jain NB. Are psychosocial factors associated with patient-reported outcome measures in patients with rotator cuff tears? A Systematic Review. Clin Orthop. 2018;476:810-29.

64. Fan ZJ, Silverstein BA, Bao S, Bonauto DK, Howard NL, Spielholz PO, et al. Quantitative exposure-response relations between physical workload and prevalence of lateral epicondylitis in a working population. Am J Ind Med. 2009;52:479-90.

65. Geoghegan JM, Clark DI, Bainbridge LC, Smith C, Hubbard R. Risk factors in carpal tunnel syndrome. J Hand Surg. 2004;29:315-20.

66. Haahr JP, Andersen JH. Physical and psychosocial risk factors for lateral epicondylitis: a population based case-referent study. Occup Environ Med. 2003:60:322-9.

67. Harris-Adamson C, Eisen EA, Kapellusch J, Garg A, Hegmann KT, Thiese MS, et al. Biomechanical risk factors for carpal tunnel syndrome: a pooled study of 2474 workers. Occup Environ Med. 2015;72:33-41.

68. Harris-Adamson C, Eisen EA, Dale AM, Evanoff B, Hegmann KT, Thiese MS, et al. Personal and workplace psychosocial risk factors for carpal tunnel syndrome: a pooled study cohort. Occup Environ Med. 2013;70:529-37.

69. Kraatz S, Lang J, Kraus T, Münster E, Ochsmann E. The incremental effect of psychosocial workplace factors on the development of neck and shoulder disorders: a systematic review of longitudinal studies. Int Arch Occup Environ Health. 2013;86:375-95

70. Mansfield M, Thacker M, Sandford F. Psychosocial risk factors and the association with carpal tunnel syndrome: a systematic review. HAND. 2018;13:501-8.

71. Mayer J, Kraus T, Ochsmann E. Longitudinal evidence for the association between work-related physical exposures and neck and/or shoulder complaints: a systematic review. Int Arch Occup Environ Health. 2012;85:587-603. 
72. Roquelaure Y, Bodin J, Ha C. Petit Le Manac'h a, Descatha a, Chastang J-F, et al. personal, biomechanical, and psychosocial risk factors for rotator cuff syndrome in a working population. Scand J Work Environ Health. 2011;37:502-11.

73. Melchior M, Roquelaure Y, Evanoff B, Chastang J-F, Ha C, Imbernon E, et al. Why are manual workers at high risk of upper limb disorders? The role of physical work factors in a random sample of workers in France (the pays de la Loire study). Occup Environ Med. 2006;63:754-61.

74. Hagberg M, Morgenstern H, Kelsh M. Impact of occupations and job tasks on the prevalence of carpal tunnel syndrome. Scand J Work Environ Health. 1992:337-45. MID: 1485158 https//doi.org/10.5271/sjweh.1564.

75. Belin A, Dupont $C$, Oulès L, Kuipers Y. Safer and healthier work at any age final overall analysis report. Luxembourg: European Agency for Safety and Health at Work; 2016.

76. Leclerc A, Landre M-F, Chastang J-F, Niedhammer I, Roquelaure Y, Work SG on R. Upper-limb disorders in repetitive work. Scand J Work Environ Health. $2001268-278$

77. van Rijn RM, Huisstede BM, Koes BW, Burdorf A. Associations between workrelated factors and the carpal tunnel syndrome-a systematic review. Scand J Work Environ Health. 2009:35:19-36.

78. Harkness EF, MacFarlane GJ, Nahit ES, Silman AJ, McBeth J. Mechanical and psychosocial factors predict new onset shoulder pain: a prospective cohort study of newly employed workers. Occup Environ Med. 2003;60:850-7.

79. Shiri R, Pourmemari MH, Falah-Hassani K, Viikari-Juntura E. The effect of excess body mass on the risk of carpal tunnel syndrome: a meta-analysis of 58 studies: obesity and carpal tunnel syndrome. Obes Rev. 2015;16:1094-104.

80. Werner RA, Albers JW, Franzblau A, Armstrong TJ. The relationship between body mass index and the diagnosis of carpal tunnel syndrome. Muscle Nerve. 1994;17:632-6.

81. Werner RA, Franzblau A, Albers JW, Armstrong TJ. Influence of body mass index and work activity on the prevalence of median mononeuropathy at the wrist. Occup Environ Med. 1997;54:268-71.

82. Miranda H, Viikari-Juntura E, Martikainen R, Takala EP, Riihimäki H. A prospective study of work related factors and physical exercise as predictors of shoulder pain. Occup Environ Med. 2001;58:528-34.

83. Luime JJ, Kuiper Jl, Koes BW, Verhaar JA, Miedema HS, Burdorf A. Workrelated risk factors for the incidence and recurrence of shoulder and neck complaints among nursing-home and elderly-care workers. Scand J Work Environ Health. 2004;30:279-86.

84. Descatha A, Dale AM, Jaegers L, Herquelot E, Evanoff B. Self-reported physical exposure association with medial and lateral epicondylitis incidence in a large longitudinal study. Occup Environ Med. 2013;70:670-3.

85. Freivalds A. Biomechanics of the upper limbs: mechanics, modeling and musculoskeletal injuries. 2nd ed: CRC Press; 2011. https://doi.org/10.1201/b11547.

86. Burt S, Deddens JA, Crombie K, Jin Y, Wurzelbacher S, Ramsey J. A prospective study of carpal tunnel syndrome: workplace and individual risk factors. Occup Environ Med. 2013;70:568-74

87. Leong H, Fu S, He X, Oh J, Yamamoto N, Yung S. Risk factors for rotator cuff tendinopathy: a systematic review and meta-analysis. J Rehabil Med. 2019; 51:627-37.

88. Bildt C, Alfredsson L, Punnett $L$, Theobald $H$, Torgén M, Wikman A. Effects of drop out in a longitudinal study of musculoskeletal disorders. Occup Environ Med. 2001;58:194-9.

89. Rockhill B, Weinberg CR, Newman B. Population attributable fraction estimation for established breast Cancer risk factors: considering the issues of high prevalence and Unmodifiability. Am J Epidemiol. 1998;147:826-33.

90. van der Windt DA, Thomas E, Pope DP, de Winter AF, Macfarlane GJ, Bouter LM, et al. Occupational risk factors for shoulder pain: a systematic review. Occup Environ Med. 2000;57:433-42.

91. Benichou J. Biostatistics and epidemiology: measuring the risk attributable to an environmental or genetic factor. C R Biol. 2007;330:281-98.

92. St-Vincent $M$, Vézina N, Bellemare M, Denis D, Ledoux É, Imbeau D. Ergonomic intervention. BookBaby: Cork; 2014.

93. Winkel J, Westgaard RH. Development and implementation of interventions managing work-related musculoskeletal disorders: inadequacy of prevalent research framework and future opportunities. Scand J Work Environ Health. 2019;45:316-7.

\section{Publisher's Note}

Springer Nature remains neutral with regard to jurisdictional claims in published maps and institutional affiliations.

Ready to submit your research? Choose BMC and benefit from:

- fast, convenient online submission

- thorough peer review by experienced researchers in your field

- rapid publication on acceptance

- support for research data, including large and complex data types

- gold Open Access which fosters wider collaboration and increased citations

- maximum visibility for your research: over $100 \mathrm{M}$ website views per year

At BMC, research is always in progress.

Learn more biomedcentral.com/submissions 